\title{
Medical Rehabilitation of Patients with Chronic Obstructive Pulmonary Disease Using Manipulative Action Techniques
}

\author{
Nina Stepenovna Ayrapetova', Michael Anatolievich Eremushkin 2, *, \\ Igor Vyacheslavovich Antonovich ${ }^{2}$, Alexey Egorovich Samorukov ${ }^{2}$, Larisa Yurievna Tarasova ${ }^{3}$ \\ ${ }^{1}$ Department of Pulmonology, Rehabilitation and Spa Medicine National Medical Research Center Ministry of Health, Moscow, Russian \\ Federation \\ ${ }^{2}$ Department of Clinical Biomechanics and Physiotherapy, Rehabilitation and Spa Medicine National Medical Research Center Ministry of \\ Health, Moscow, Russian Federation \\ ${ }^{3}$ Department of Functional Diagnostics Rehabilitation and Spa Medicine National Medical Research Center Ministry of Health, Moscow, \\ Russian Federation
}

Email address:

info@medmassage.ru (M. A. Eremushkin)

${ }^{*}$ Corresponding author

\section{To cite this article:}

Nina Stepenovna Ayrapetova, Michael Anatolievich Eremushkin, Igor Vyacheslavovich Antonovich, Alexey Egorovich Samorukov, Larisa Yurievna Tarasova. Medical Rehabilitation of Patients with Chronic Obstructive Pulmonary Disease Using Manipulative Action Techniques. Rehabilitation Science. Vol. 3, No. 2, 2018, pp. 33-37. doi: 10.11648/j.rs.20180302.12

Received: May 24, 2018; Accepted: June 14, 2018; Published: July 10, 2018

\begin{abstract}
This study was conducted to evaluate the efficiency of manipulative action techniques in complex treatment of patients with chronic obstructive pulmonary disease and represents the results of clinical and functional tests. Differentiated indications for use of different techniques of chest massage and manual therapy were proposed. Parallel group randomized prospective comparative study was conducted on 137 patients with COPD. In accordance with the classification (GOLD, 2013), all patients were diagnosed with COPD of medium severity. $75(54.7 \%)$ patients had persistent disease, $80(58.4 \%)$ and 57 (41.6\%) patients suffered from respiratory insufficiency of I and II degree, respectively. Respiration function was assessed by pneumotachometry study performed during forced expiratory maneuvers and by spirometry methods; pulmonary hemodynamics and myocardial contractile function of the right ventricle were assessed by reopulmonography methods; central hemodynamics was assessed by tetrapolar thoracic rheography. The research led to the following overall findings. The massage technique focused on asymmetric areas of the chest develops the most active anti-inflammatory action as compared to other physical impact techniques we investigated. This technique should be used with caution in the presence of hypokinetic type of blood circulation and pulmonary hypertension. The classical massage technique of the chest has the advantage as we can consider the possibility to prescribe this technique to patients with more severe course of COPD, including but not limited to presence of pulmonary and systemic cardiac hemodynamic disorders, alveolar hypoxia.
\end{abstract}

Keywords: Pulmonary Disease, Medical Rehabilitation, Classical Massage, Manual Therapy

\section{Introduction}

Nowadays, significant increase in chronic obstructive pulmonary disease (COPD) prevalence, run up to $10.1 \%$ among individuals that are on the wrong side of forty, raise a reasonable concern. COPD takes up the second place amongst noncommunicable disease and leads by such values like number of day of disability and invalidity. COPD is one and only disease associated with continued increasing mortality. All mentioned above set up an acute health and social significance in regard of new treatment and rehabilitative options development for this patient population [1-4].

Pursuant to pathogenesis of COPD, the key role pertains to inflammatory process which remains latent even at remission and triggering the bronchial obstruction development. With the aggravation of pathological process we observe the growth of pulmonary ventilation and respiratory metabolism disorders, development of pulmonary hypertension, chronic cor pulmonale. Relapsing, irreversibly progressive course of 
disease entails to administer treatment regularly; however, permanent use of large range of pharmaceutical substances necessarily leads to development of well-known side effects and complications. At the same time, the absence of antiinflammatory drugs on the pharmaceutical market, at once effective and safe, is of substantial significance [2,5]. Within the given context, it's reasonable to additionally include in the treatment guidelines for COPD patients drug-free techniques, able to exert corrective impact on the key pathogenetic mechanisms of the disease [6-8].

With the view of intensification of anti-inflammatory action, improvement of hemocirculation and ventilation function of lungs, the classical massage technique of the chest is traditionally used. In order to improve effectiveness of therapeutic intervention, O. F. Kuznetsov (1987) [9] developed and embedded to practice innovative method - the intensive massage technique focused on asymmetric areas of the chest. Rationale for his development served results, describing presence of fragmentary musculocutaneous deformations of thoracoabdominal area associated with respiratory system pathology; in addition, zones of hypertrophy and hypotrophy are sited diagonally, akin to "draw game". Considering that hypotrophy zones correspond to allocation of inflammatory-anatomical alterations in tissues, we can intentionally change pathologic behavior [9, 10]. Over the last years come out messages about the positive implication of manual therapy when it's used to treat patients with respiratory system pathologies. Application of this technique is based on insight that segmental associated body parts could interwork due to close nervous, endocrine and humoral associations [11-14].

Study objective: to identify clinical features and benefits of different chest physical impact techniques in patients diagnosed with COPD and to develop selective indications for it's prescription.

\section{Materials and Methods}

Parallel group randomized prospective comparative study was conducted on 137 patients with COPD (83 - male, and 54 - female subjects, mean age $-51.9 \pm 7.4)$. In accordance with the classification (GOLD, 2013), all patients were diagnosed with COPD of moderate severity. 75 (54.7\%) patients had persistent disease, 80 (58.4\%) and 57 (41.6\%) patients suffered from respiratory insufficiency of I and II degree, respectively.

Inclusion criteria were: medium severity COPD case in complete or partial remission; respiratory failure equal to or less then II stage; age range from 38 to 65 years. Exclusion criteria were: mild, severe or very severe COPD case; exacerbation of inflammatory process; presence of serious concomitant disease, requiring medications adjustment.

Identification of current inflammatory process relied on the assessment of clinical characteristics of the disease and laboratory tests results: morphological composition of peripheral blood, biochemical inflammation equivalents $(\mathrm{C}$ reactive protein, ceruleoplasmin, hexoses). Respiration function was assessed by pneumotachometry study performed during forced expiratory maneuver and by spirometry methods. Pulmonary hemodynamics and myocardial contractile function of the right ventricle were assessed by reopulmonography method; central hemodynamics was assessed by tetrapolar thoracic rheography.

Routine immunological tests were run to determine the state of immunocompitent system: determination of T-cells and B-cells, pattern of thymocyte subpopulations and their capacity, serum IgG, IgA and IgM levels, circulating immune complexes.

Statistical analysis of obtained results was performed with software package "Statistics for Windows 6.0". Differences between mean values were assessed by Student t-test and were considered statistically significant when $p<0.05$.

\section{Results}

Chief complaints of COPD patients were cough, commonly paroxysmal in nature, mucous and mucopurulent expectoration, rough breathing, expiratory dyspnea events, and exertional dyspnea. Persistent disease (54.7\%) was indicated by definitive clinical implications and laboratory tests results. Respiratory function disorders include bronchial obstruction development, mainly at distal segments, decrease of lung volume, presence of alveolar hypoxia. Change in myocardial contractile function of the right ventricle was defined by increase in arterial blood pressure in pulmonary artery system, associated with increase of vascular resistance and venostasis, abnormal phase structure of right ventricular systole. General circulation analysis revealed more often hyperkinetic $(54.0 \%)$, less commonly hypokinetic $(23.3 \%)$ or eukinetic $(22.7 \%)$ hemocirculation type. Failure of immune protection characteristically exhibit depression of the cellular component and activation of humoral component of immune system.

As per research goals all patients were assigned to 3 treatment arms, identical by clinical and functional profile. By the way of rehabilitation technique, patients in the $1^{\text {st }}$ group (46 patients) were assigned to be treated with classical massage of the chest, $2^{\text {nd }}$ ( 47 patients) - massage focused on asymmetric areas of the chest, $3^{\text {rd }}$ (44 patients) - manual therapy.

Classical massage technique involve subsequent conduction of basic maneuvers: stroking, rubbing, foulage, fremitus, performed along the lymphatic vessels. Manipulations, lasting for 15 minutes, were assigned on a daily basis, 10 manipulations per treatment course.

During the massage focused on asymmetric areas of the chest manipulations were performed, based on distribution of musculocutaneous hypertrophy zones, in two variations: $1^{\text {st }}$ involved superior lobe of left lung, middle and lower lobe of right lung zone projections, $2^{\text {nd }}$ - superior lobe of right lung, lower and lingular lobe of left lung. After the first manipulation variations were interchanged. Manipulation started with massage of two zones on the anterior surface of 
the chest, following with two zones on the posterior surface of the chest. Initially inferior zones were massed, afterwards - superior; each zone was massed on two occasions. As well, the clinical features of the technique were increase of the exposure duration and proportion of vibration maneuvers over stroking. The duration of the massage was 30 minutes, the course of massage consisted of 6 manipulations, assigned every second day.

In the course of manual therapy the following maneuvers were used: postisometric relaxation (on trapezius muscle, rhomboid muscle, rotators and extensors of cervical spine, elevator muscle of scapula), mobilization (in the region of sternoclavicular, costosternal, costotransverse joints), directional manipulations (at the level of $\mathrm{C}_{0}-\mathrm{C}_{\mathrm{I}}, \mathrm{C}_{\mathrm{VII}}-\mathrm{Th}_{\mathrm{I}}$ metameres, and costotransverse joints: $\mathrm{Th}_{\mathrm{III}}-\mathrm{Th}_{\mathrm{IV}}, \mathrm{Th}_{\mathrm{VI}^{-}}$ $\left.\mathrm{Th}_{\mathrm{VII}}\right)$. Manipulations, lasting for 15-20 minutes, were assigned every second day; the course of manual therapy consisted of 6 manipulations.

After the treatment course with specified techniques the following pattern was indicated within the majority of the patients: interruption or involution of the cough, reduction of sputum expectoration and decrease of pyogenesis, breathing relief, decreased intensity of dyspnea, well-being improvement and physical signs regression. Special methods of investigation results demonstrated positive dynamics.

Dynamics of inflammatory process activity was assessed within the patient group with initially modified levels of haemogram profile. It was detected that most apparent antiinflammatory action comes with intensive massage. That was indicated by distinct decrease of white blood cell count (from $11.13 \pm 0.68 \times 10^{9}$ to $8.61 \pm 0.47 \times 10^{9} \quad 1, \quad \mathrm{p}<0.02$ ), band neutrophile (from $6.25 \pm 0.40$ to $4.32 \pm 0.53 \%, \mathrm{p}<0.02$ ), ESR (from $21.38 \pm 1.47$ to $15.23 \pm 1.13 \mathrm{~mm} / \mathrm{h}, \mathrm{p}<0.01$ ), hexoses (from $1.45 \pm 0.032$ to $1.27 \pm 0.038 \mathrm{~g} / \mathrm{l}, \mathrm{p}<0.002$ ), ceruleoplasmin (from $451.3 \pm 10.7$ to $407.2 \pm 17.3 \mathrm{mg} / \mathrm{l}$, $\mathrm{p}<0.05$ ), C-reactive protein (from $1.54 \pm 0.17$ to $0.46 \pm 0.17$ $\mathrm{CU}, \mathrm{p}<0.001)$. Reportedly, inflammation regression, in some degree, was associated with activation of glucocorticoid activity produced by suprarenal cortex, as confirmed by elevation of 11-oxycorticosteroids in blood (from $320.5 \pm 5.81$ to $368.2 \pm 12.30 \mathrm{nM} / 1, \mathrm{p}<0.01$ ).

Classical massage technique also lead to inflammation regress, however it was comparatively less effective $(p<0.05$ 0.02). Manual therapy course didn't exert significant influence on the inflammatory process state $(p>0.5)$.

After the course of treatment it was registered the obvious improvement of impaired immunogenesis function within the patients of the $2^{\text {nd }}$ group, treated with intensive massage. Along with quantitative elevation of T-cells (from $25.7 \pm 1.53$ to $35.6+2.09 \%, \quad \mathrm{p}<0.002$; in absolute values - from $548.7 \pm 40.4$ to $732.8+48.0 \mathrm{abs} / 1 \times 10^{6}, \mathrm{p}<0.01$ ), increase of their functional activity was also detected, confirmed by increased values of blastogenesis test - blast-transformation reaction (from $29374 \pm 2550$ to $46531 \pm 5493$ count per minute, $\mathrm{p}<0.02$ ) and stimulation index (from $24.8 \pm 1.67$ to $37.2 \pm 3.40$, $\mathrm{p}<0.01)$. At the same time, we observe reduction of spontaneous lymphocyte proliferation intensity (from
$3123 \pm 373$ to $1546 \pm 399$ count per minute, $\mathrm{p}<0.02$ ), which is thought to be consequent to antigenic excitation decrease in the context of inflammatory process involution. Changes in the pattern of lymphocyte subpopulations as presented by the increase of initially reduced T-helper cell level (from $14.1 \pm 1.20$ to $18.9 \pm 1.73 \%, \mathrm{p}<0.05$; in absolute values - from $152.7 \pm 14.7$ to $\left.226.8 \pm 27.3 \mathrm{abs} / 1 \times 10^{6}, \mathrm{p}<0.05\right)$ and decrease of too high T-killer cell level (from $21.9 \pm 1.21$ to $16.4 \pm 1.47 \%$, $\mathrm{p}<0,02$; in absolute values - from $273.7 \pm 20.8$ to $187.5 \pm 26.8$ $\left.\mathrm{abs} / 1 \times 10^{6}, \mathrm{p}<0.05\right)$ lead to rise of immunoregulatory index (from $1.13 \pm 0.04$ to $1.42 \pm 0.09, \mathrm{p}<0.01$ ). Improvement of cellmediated immunity function was accompanied by correction of humoral component of immune system function: decrease of initially elevated number of B-lymphocytes (from $30.6 \pm 1.39$ to $23.1 \pm 1.98 \%, \mathrm{p}<0.01$; in absolute values - from $692.8 \pm 47.6$ to $\left.478.3 \pm 59.3 \mathrm{abs} / 1 \times 10^{\sigma}, \quad \mathrm{p}<0.02\right)$, was accompanied by unidirectional dynamics of $\mathrm{IgG}$ (from $16.28 \pm 0.44$ to $13.86 \pm 0.38 \mathrm{~g} / 1, \mathrm{p}<0.001$ ), $\operatorname{IgA}$ (from $2.80 \pm 0.10$ to $2.41 \pm 0.11 \mathrm{~g} / \mathrm{l}, \mathrm{p}<0.02$ ), $\operatorname{IgM}$ (from $2.68 \pm 0.13$ to $1.81 \pm 0.16$ $\mathrm{g} / \mathrm{l}, \mathrm{p}<0.05$ ) and circulating immune complex - CIC (from $0.173 \pm 0.008$ to $0.142 \pm 0.009, \mathrm{p}<0.02$ ).

After the course of classical massage $\left(1^{\text {st }}\right.$ group) the changes in indices, specific for cellular and humoral immunity, were statistically of lower value, while T-killer cells concentration changed a little $(p>0.5)$. Manual therapy treatment $\left(3^{\text {rd }}\right.$ group) was associated with moderate rise of count and proliferative capacity of thymocytes, improvement in cell subpopulations ratio, decrease in percentage of Blymphocytes count and level of $\operatorname{IgG}(\mathrm{p}<0.05)$.

Medical and rehabilitation activities contribute to improvement of the respiratory system functional status. Within the patients of the $1^{\text {st }}$ group, been treated with classical massage, it was registered: reduction of bronchial obstruction $\left(\mathrm{FEV}_{1}\right.$ elevation - from $67.4 \pm 2.67$ to $74.6 \pm 2.29 \% ; \mathrm{p}<0.05)$ at the level of large (PEF increase from $74.5 \pm 1.75$ to $79.4 \pm 1.68 \% ; \mathrm{p}<0.05 ; \mathrm{V}_{25}$ increase - from $63.7 \pm 2.10$ to $70.3 \pm 1.75 \% ; \mathrm{p}<0.02)$, medium $\left(\mathrm{V}_{50}\right.$ increase from $48.2 \pm 2.13$ to $54.9 \pm 1.56 \% ; \quad \mathrm{p}<0.02)$ and small $\left(\mathrm{V}_{75}\right.$ increase - from $39.6 \pm 2.29$ to $45.2 \pm 1.41 \%$; $\left.<<0.05\right)$ airways, increasing of lung capacity ratio (from $82.9 \pm 3.79 \%$ to $93.3 \pm 3.23 \% ; \mathrm{p}<0.05$ ). Elevation of airway conductance and lung volumes was associated with decrease of alveolar hypoxia: it was confirmed by decrease of excessive oxygen consumption during the $1^{\text {st }}$ minute - oxygen consumption test (from $121.3 \pm 4.49$ to $108.0 \pm 4.24 \%$; $\mathrm{p}<0.01$ ) and increase oxygen uptake by tissues - oxygen utilization quotient (from $30.9 \pm 1.97$ to $37.0 \pm 1.82 \mathrm{ml} ; \mathrm{p}<0.05)$. Ventilation and gas exchange functions improvement resulted in high-level activity of compensatory ventilation mechanisms (decrease of pulmonary minute volume - from $159.4 \pm 7.17$ to $134.5 \pm 6.56 \% ; \mathrm{p}<0.02)$.

Treatment with intensive massage ( $2^{\text {nd }}$ group) was associated with statistically more distinct, as compared with classical technique, rise of lung volumes (lung capacity; $\mathrm{p}<0.02$ ) and airway patency on the level of large bronchi (PEF, $\mathrm{V}_{25} ; \mathrm{p}<0.01$ ). At the same time, drenching the tissues with oxygen was less apparent (oxygen utilization quotient; 
$0.05<\mathrm{p}<0.1)$, and there was no impact of the technique on hyperventilation $(p>0.5)$. Manual therapy manipulations $\left(3^{\text {rd }}\right.$ group) lead to reduction of bronchial obstruction of large (PEF, $\left.\mathrm{V}_{25} ; \mathrm{p}<0.02\right)$ and medium bronchi $\left(\mathrm{V}_{50} ; \mathrm{p}<0.05\right)$, increase of lung capacity $(\mathrm{p}<0.05)$.

Manipulative action techniques exert favorable effect on pneumonic cardiac hemodynamic. Decreased pulmonary vascular resistance (shortening of slow ejection phase from $0.161 \pm 0.0097$ to $0.132 \pm 0.0079 \mathrm{RU}, \mathrm{p}<0.02$; increased mean speed of slow ejection - from $0.38 \pm 0.035$ to $0.49 \pm 0.030 \mathrm{Ohm} / \mathrm{s}, \mathrm{p}<0.02$ ) along with distinct increase of venous drainage (SDR - from $1.29 \pm 0.071$ to $1.53 \pm 0.055 \mathrm{RU}, \mathrm{p}<0.01)$ as a result of classical massage treatment $\left(1^{\text {st }}\right.$ group) lead to decrease of pulmonary arterial pressure (shortening of tension period - from $0.148 \pm 0.0041$ to $0.137 \pm 0.0033 \mathrm{sec}, \mathrm{p}<0.05)$. It was attended by improvement of myocardial contractile function of the right ventricle (shortening of tension period, slow ejection phase, elongation of rapid ejection phase, increase of the peak speed of rapid ejection), raise of ejection fraction (increase of the peak speed of rapid ejection from $2.08 \pm 0.107$ to $2.37 \pm 0.095 \mathrm{Ohm} / \mathrm{s}, \mathrm{p}<0.05$ ) and pulse blood filling of the lungs (increase of RI from $2.18 \pm 0.121$ to $2.51 \pm 0.096$ Ohm, $\mathrm{p}<0.05)$.

In contrast, treatment with the intensive massage technique ( $2^{\text {nd }}$ group) lead to apparent raise of ejection fraction of right ventricle (increase of the peak speed of rapid ejection from $2.15 \pm 0.086$ to $2.61 \pm 0.118 \mathrm{Ohm} / \mathrm{s}, \mathrm{p}<0.002)$ and pulmonary volumetric blood flow (increase of RI from $2.20 \pm 0.130$ to $2.64 \pm 0.104 \mathrm{Ohm}, \mathrm{p}<0.01$ ); decrease of vascular resistance and venostasis was comparatively moderate $(p<0.05)$, pulmonary arterial pressure didn't change. The course of manual therapy ( $3^{\text {rd }}$ group) lead to decrease of great tonicity of pulmonary arterioles (shortening of slow ejection phase, raise of mean speed of slow ejection, $\mathrm{p}<0.05$ ), improvement of venous drainage (SDR, $\mathrm{p}<0.05$ ), have a tendency to raise the ejection fraction of right ventricle (peak speed of rapid ejection $-0.05<\mathrm{p}<0.1)$.

Better results, pertinent to reorganization of systemic hemodynamic activity, as well, were observed following the treatment with classical massage $\left(1^{\text {st }}\right.$ group $)$, particularly in patients with initial hyperkinesia of heart (19 patients): reduction of cardiac index (from $4.57 \pm 0.25$ to $3.70 \pm 0.22$ $1 / \mathrm{min} / \mathrm{m}^{2}, \mathrm{p}<0.02$ ), as a result of unidirectional change of systolic output index (from $66.8 \pm 2.24$ to $59.2 \pm 1.85 \mathrm{ml} / \mathrm{m}^{2}$ $(\mathrm{p}<0.02)$, and rising of peripheral resistance $-\mathrm{TPR}$ (from $18.7 \pm 1.15$ to $24.6 \pm 1.79 \mathrm{RU}, \mathrm{p}<0.02$ ) were noted. Similar dynamics of specified indices was also observed with hyperkinetic circulation patients after the courses of intensive massage and manual therapy $\left(2^{\text {nd }}\right.$ and $3^{\text {rd }}$ groups $)$, however it was less apparent $(\mathrm{p}<0.05)$.

Following the courses of classical massage and manual therapy $\left(1^{\text {st }}\right.$ and $3^{\text {rd }}$ groups $)$, patients with hypokinetic type of systemic hemodynamic demonstrated consistent changes, which include elevation of cardiac and systolic output indices, decrease of peripheral resistance $(p<0.05)$. Intensive massage treatment ( $2^{\text {nd }}$ group) of patients with hypokinetic heart (11 patients) lead to noticeable improvement performance of the left ventricle (increase of cardiac index from $1.94 \pm 0.18$ to $2.72 \pm 0.29 \mathrm{l} / \mathrm{min} / \mathrm{m}^{2}, \mathrm{p}<0.02$, primarily as a result of systolic output index elevation - from $32.7 \pm 3.49$ to $47.9 \pm 5.09 \mathrm{ml} / \mathrm{m}^{2}, \mathrm{p}<0.05$ ), herewith there were no evident changes of peripheral resistance $(p>0.5)$. Noticeable, that application of intensive technique arise trend to systolic output index elevation $(0.05<\mathrm{p}<0.1)$ within the patients with eukinetic type of systemic hemodynamic. To be noticed is that treatment of few patients with hypokinetic type of systemic hemodynamic and pulmonary hypertension with the intensive massage technique was accompanied by tachycardia, dyspnea, feeling tired and fatigue. It seems that it could be connected with excessive blood flow to the heart under reduced compensation abilities.

Marked positive changes of clinical and functional COPD patient's condition following the course of classical and intensive massage defined high-potency of the treatment $88.1 \%$ and $90.7 \%$ accordingly. It was statistically more significant $(\mathrm{p}<0.05)$, alternatively to manual therapy $-75 \%$, that we believe is considerably related to absence of inflammatory impact of the technique.

\section{Conclusion}

The intensive massage technique focused on asymmetric areas of the chest possesses the most active antiinflammatory action, as compared to other techniques of physical impact we have investigated. This technique should be used with caution in the presence of hypokinetic type of blood circulation and pulmonary hypertension.

The classical massage technique of the chest has the advantage as we can consider the possibility to prescribe this technique to patients with more severe course of COPD, including but not limited to presence of pulmonary and systemic cardiac hemodynamic disorders, alveolar hypoxia.

Manual therapy is the treatment of choice in patients with COPD in remission and in the presence of concomitant functional blockage of vertebral segments.

In summary, results of the research study prove usefulness and high effectiveness of different massage and manual impact techniques, and serve as basis for their inclusion in medical rehabilitation guidelines for management of COPD patients. Improvement of the effectiveness of the indicated techniques could be reached with selective prescription accordingly to disease pattern.

\section{Authors' Contribution}

Theory and study design - H. A., M. E., O. K.

Collection and processing of data: И. А., А. С., С. Б., Л. Т., Н. Д.

Statistical processing of data - И. А.

Writing - H. A.

Editorial revision - M. E. 


\section{References}

[1] Arhipov V. V. Chronic obstructive pulmonary disease: pharmacoeconomic aspects. Pulmonology. 2010, 4: 99-103.

[2] Chuchalin A. G. Epidemiology of chronic obstructive pulmonary disease in Russia: new data GARD project. Consilium medicum. Ekstravypusk. Media medice. 2011: 134.

[3] The global strategy of diagnosis, treatment and prevention of chronic obstructive pulmonary disease (GOLD, 2013 revision). M.: atmosphere. 2014: 96.

[4] Buist AS, McBurnie MA, Vollmer WM et al. International variation in the prevalence of COPD (the BOLD Study): a population-based prevalence study. Lancet. 2007, 370: 741750.

[5] Shmelev E. I. Chronic obstructive pulmonary disease. Proc.: Chuchalin AG (Eds.) Pulmonology. National leadership. M.: GEOTAR Media; 2009: 303-447.

[6] Ajrapetova N. S. Chronic obstructive pulmonary disease: treatment, rehabilitation, prevention. Physiotherapy, balneology and rehabilitation. 2009, 1: 46-54.

[7] Rassulova M. A., Ajrapetova N. S. Influence naphthalan treatment on clinical and functional status of patients with chronic obstructive pulmonary disease. Issues. kurortol., fizioter. and physical therapy. - 2007, 1: 19-21.

[8] Ajrapetova N. S., O. V. Nitchenko, OV Kulikova, Antonovich I. V., Ujanaeva M. A. On the question of whether to include common baths with biolong in rehabilitation complex patients with obstructive respiratory diseases. Problems of Balneology, Physiotherapy and Exercise Therapy. 2014. 4: 7-13.

[9] Kuznecov O. F. The effectiveness of new methods of intensive massage and physiotherapy in the rehabilitation of patients with chronic non-specific lung diseases (chronic pneumonia, chronic bronchitis). Author. diss... Doc. honey. Sciences. - M. 1987: 43.

[10] Ajrapetova N. S., Kuznecov O. F., Samorukov A. E. The use of different types of massage and manual actions in the rehabilitative treatment of patients with obstructive bronchitis. Agrokurort. 2000, 3: 40-5.

[11] Gusmanov A. M., Vecherova S. A., Cyganova O. M., Babushkina G. V. Effect of manual therapy in the formation of zones of hypersensitivity Zakharyin-Ged. Proc.: Act. Restore problems. med., resort. and fiziot. Mater. international. Congress "health resort-2005". M; 2005: 76.

[12] Trubnikov G. A., Orlov M. A., Polunina O. S., Orlova E. A., Ivanov A. A., Timoshin S. A., Murzamuratova N. I. The use of non-pharmacological methods (orthodox) and traditional medicine in the rehabilitation of patients with chronic obstructive pulmonary disease. Proc.: Baikal Readings-2. Ed. prof. AN Coconut. St. Petersburg; Special literature. 2005: 125-8.

[13] Li I. L. Diagnosis and treatment of pain in the chest by manual therapy. Author. diss. MD... M. 2005: 21.

[14] Samorukov A. E., Budylin S. P., Magomedov M. K., Ajrapetova N. S. Manual therapy in complex regenerative treatment with sodium chloride baths patients with chronic obstructive bronchitis. Manual therapy. - 2014, 2 (54): 63-70. 